\title{
Stereoselective Synthesis of Alkylidene Phthalides
}

\author{
Andrei Dragan, D. Heulyn Jones, Alan R. Kennedy and Nicholas C. O. Tomkinson*
}

WestCHEM, Department of Pure and Applied Chemistry, Thomas Graham Building, University of Strathclyde, 295 Cathedral Street, Glasgow, G1 1XL, U.K.

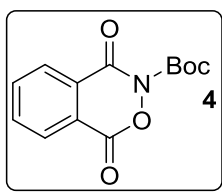

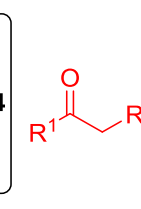

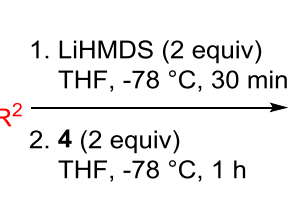

15 examples

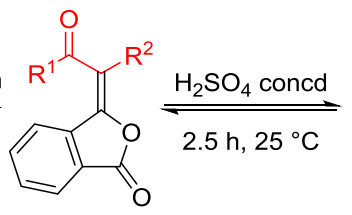

up to $83 \%$ yield

up to $6.5: 1 \mathrm{dr}$

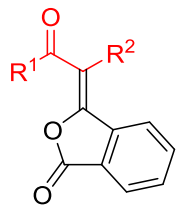

0

ABSTRACT: The N,O-diacylhydroxylamine derivative $\mathbf{4}$ has been prepared and its reactivity with nucleophiles investigated. On reaction with lithium enolates of cyclic or acyclic ketones, $\mathbf{4}$ is converted stereoselectively to the corresponding alkylidene phthalide. The stereochemical outcome of the transformation can be modified by changing the polarity of the reaction medium and the products isomerized under acidic conditions.

Natural products frequently provide the inspiration for pioneering work in drug discovery and synthesis. ${ }^{1}$ Uncovering new routes to prepare privileged fragments of biological importance ${ }^{2}$ is therefore of great interest and delivers a motivation for methodology development. ${ }^{3}$ Alkylidene phthalides and their derivatives have a rich chemistry and have received significant attention from the synthetic community. This is due to the diverse biological activities associated with the isobenzofuranone heterocyclic motif, which is present in natural products such as senkyunolide $\mathrm{E}$ and vermistatin. In addition this framework has been exploited as a versatile building block in organic synthesis (Figure 1). ${ }^{4}$

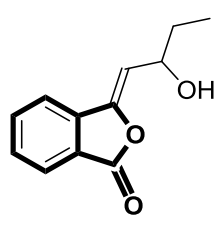

Senkyunolide E

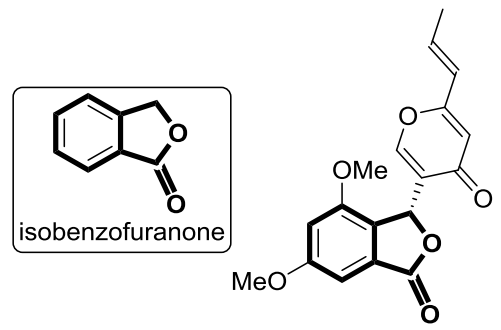

Vermistatin
Figure 1. The isobenzofuranone skeleton.

Cyclic diacyl peroxides act as electrophilic oxidizing agents of electron-rich $\pi$-systems. ${ }^{5,6}$ For example, phthaloyl peroxide $\mathbf{1}$ and its derivatives are effective in the syn-dihydroxylation of alkenes and the conversion of aromatic compounds to the corresponding phenols (Scheme 1). Phthaloyl peroxide 1 was first described as a monomer by Russell in $1955^{7}$ and its use in alkene oxidation thoroughly investigated by Greene in a series of elegant studies. ${ }^{5-e}$ Despite this insightful work, exploitation of phthaloyl peroxide as an oxidant was not revisited until 2011 when Siegel and co-workers reexamined the use of $\mathbf{1}$ in alkene syn-dihydroxylation. ${ }^{5 f}$ A potential reason for the chemistry of $\mathbf{1}$ lying dormant for such a long period may well reside in the documented explosive nature of phthaloyl peroxide and the fact this compound is reported to be very sensitive to shock. ${ }^{5 a}$ Since phthaloyl peroxides have been shown to be versatile compounds that have proved challenging to handle we were intrigued to discover if their hydroxylamine counterparts would provide more stable reagents that were reactive with nucleophiles. Within this paper we describe the preparation of the $\mathrm{N}, \mathrm{O}$ diacylhydroxylamine derivative $\mathbf{4}^{8}$ and show how reaction with enolate nucleophiles provides a simple stereoselective method for the preparation of alkylidene phthalides.

Scheme 1. Phthaloyl Peroxide as an Electrophilic Oxidant.

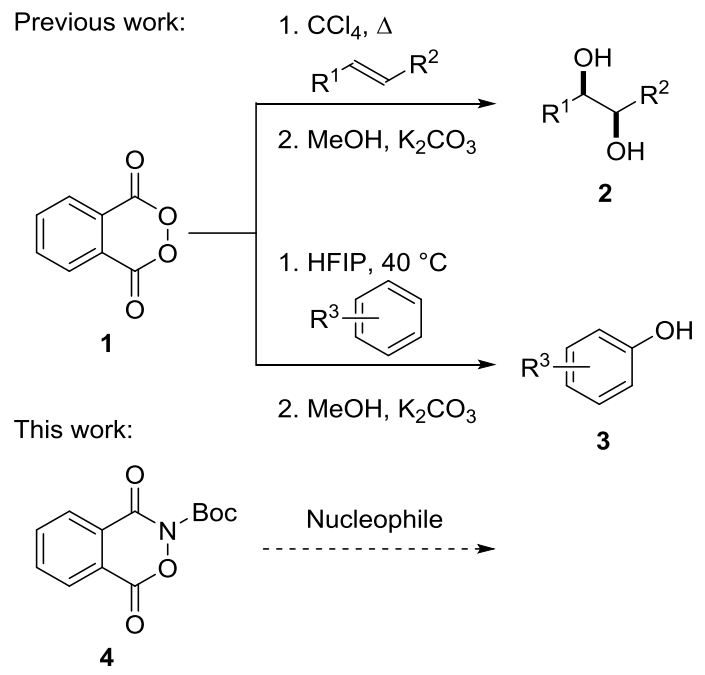

Our investigations began by treatment of commercial phthaloyl chloride with $\mathrm{N}$-Boc-hydroxylamine in the presence of triethylamine to give 4 in $56 \%$ isolated yield after purification by trituration (see Supporting Information for full details). In contrast to 
phthaloyl peroxide $\mathbf{1}$, the hydroxylamine derivative $\mathbf{4}$ proved to be a bench stable solid that was easy to manipulate and handle.

Having prepared 4 we examined its reactivity with a series of nitrogen, sulfur, oxygen and carbon nucleophiles. Whilst $\mathbf{4}$ proved less reactive than malonoyl ${ }^{6}$ and phthaloyl peroxides, ${ }^{5}$ it provided an intriguing reactivity with lithium enolates. Treatment of propiophenone 5 with one equiv of lithium hexamethyldisilazide at $-78^{\circ} \mathrm{C}$ for 30 minutes followed by addition of a THF solution of 4 and allowing the mixture to react at $-78^{\circ} \mathrm{C}$ for a further 2 hours led to the alkylidene phthalide 6 as a 4:1 mixture of diastereoisomers, the major isomer of which was isolated in $38 \%$ yield after chromatography (Scheme 2). This represented a novel and selective method for the preparation of this class of heterocycle which has been prepared previously by methods including the photolysis of epoxybenzoquinones, ${ }^{9}$ Wittig reaction of stabilized phosphonium ylides, ${ }^{10}$ carbonylative palladium catalyzed coupling of Baylis-Hillman adducts $^{11}$ and the photolysis of tricarbonyl species. ${ }^{12,13}$ Intrigued by the dense functionality introduced through this simple procedure together with the biological significance of the core structure prepared, we elected to investigate this reaction further. Selected data from the optimization of this process are collected in Table 1.

\section{Scheme 2. Preparation of Alkylidene Phthalide.}
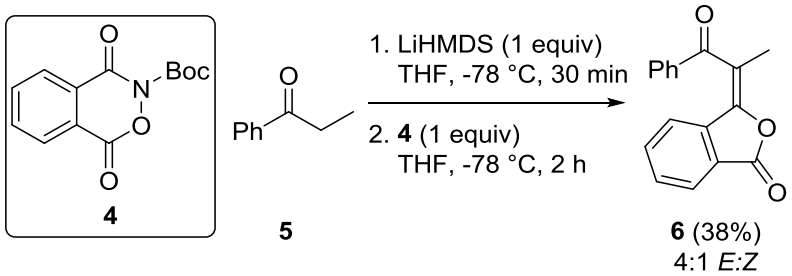

Reaction of the lithium enolate derived from 4'-methyl propiophenone 7 with 4 ( 1 equiv) led to the product 8 (23\% isolated yield) as a 5:1 mixture of diastereoisomers (Table 1, entry 1). Increasing the amount of base present to two equiv improved the amount of product significantly (Table 1, entry 2; 62\% yield, 6:1 selectivity). Three equiv of base had a detrimental effect on the reaction outcome, delivering the product in just 52\% conversion (Table 1, entry 3 ). Allowing the reaction mixture to warm to room temperature after addition of the electrophile (Table 1, entry 4) or extending the reaction time to 5 hours (Table 1 , entry 5 ) had no substantial effect on the reaction outcome. Addition of two equiv of both base and 4 resulted in complete consumption of starting material, an excellent yield and high levels of stereoselectivity (Table 1 , entry $6 ; 83 \%$ yield, $6: 1 E: Z$ ).

A potential mechanistic course for the transformation is outlined in Figure 2. The lithio-enolate 9 derived from propiophenone could add to either carbonyl group of 4 . Reaction with the $\mathrm{O}$ substituted carbonyl group would lead to $\mathbf{1 0}$ which could then deprotonate under the basic reaction conditions and ring close to give the observed product 6 . In support of this proposal, reaction of 5 under the optimized conditions gave $N$-Boc hydroxylamine 11 in $70 \%$ isolated yield. The alternative bis-electrophiles phthalic anhydride and phthaloyl chloride were examined under the optimized reaction conditions (1.0 equiv 7, 2.0 equiv LiHMDS, 2 equiv electrophile, $-78^{\circ} \mathrm{C}, 1 \mathrm{~h}$ ). In each case, no clear indication for the presence of the alkylidene phthalide product 8 was observed by ${ }^{1} \mathrm{H}$ NMR spectroscopy of the crude reaction mixture, suggesting the reactivity observed was exclusive to the phthaloyl hydroxylamine derivative 4.

Table 1. Reaction Optimization.

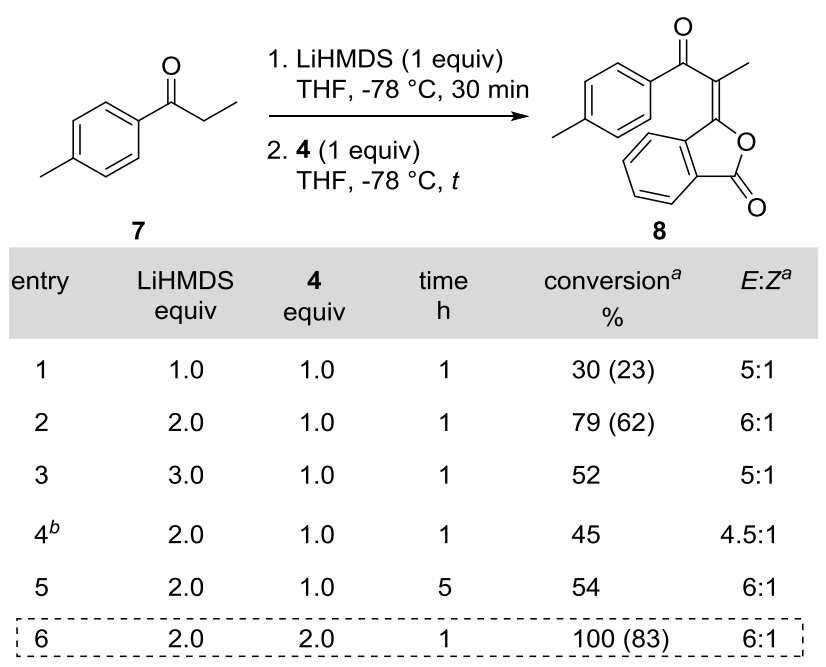

${ }^{a}$ Determined by ${ }^{1} \mathrm{H}$ NMR spectroscopy on crude reaction mixture, isolated yield of major isomer shown in parentheses; ${ }^{b}$ Reaction warmed to room temperature before stirring for $1 \mathrm{~h}$.
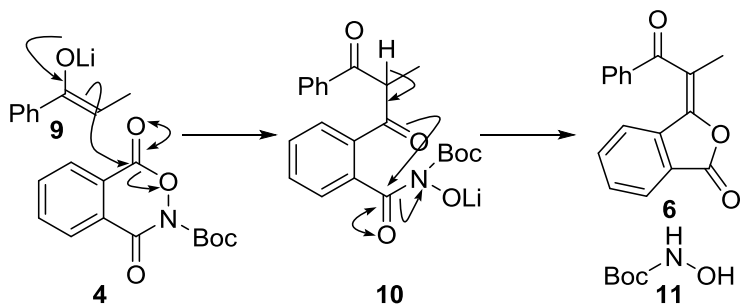

Figure 2. Potential mechanistic course for the formation of 6.

Having developed a set of optimized conditions for the reaction of 4'-methylpropiophenone, we went on to examine a series of alternative substrates within the transformation (Figure 3). Reaction of 4'-, 3'- and 2'-methylpropiophenone led selectively to the $E$ products 8, 12 and 13 in good to excellent yield (Figure 3, entries 1-3). Along with propiophenone (Figure 3, entry 4; 76\%), it also proved possible to successfully introduce both activating (Figure 3, entry 5; 56\%) and deactivating (Figure 3, entry 6; 41\%) groups onto the aromatic ring of the nucleophile. Alternative substitution at the $\alpha$-position of the ketone was also tolerated. Benzoin led to the E-product 16 with the same sense of selectivity as the propiophenone derivatives (Figure 3, entry 7; 39\%). Whilst butyrophenone gave the E-product 17 in an acceptable yield (Figure 3, entry $8 ; 47 \%)$, branching of the ketone at the $\beta$-position was less well tolerated (Figure 3, entry 9; 19\%). Using 3-pentanone, it was found that the stereochemical outcome of the transformation could be manipulated simply by changing the polarity of the reaction medium (Figure 3, entries 10-12). Using THF as the solvent delivered the $Z$-isomer 19 selectively ( $E: Z 1: 6$; isolated yield of the $Z$-isomer $48 \%$ ), whereas using HMPA as a co-solvent delivered both products in a 1:1 ratio, the $Z$-isomer being isolated in $43 \%$ yield (Figure 3 , entry 11 ). Use of toluene as the reaction medium again provided the $Z$-isomer selectively, but the transformation was significantly less efficient than under the optimized conditions (Figure 3, entry 
$12 ; 23 \%$ yield). Cyclic ketones also proved to be effective substrates within the transformation, cyclohexanone delivering the E-product in $63 \%$ isolated yield (Figure 3, entry 13 ) and cyclopentanone delivering the product $\mathbf{2 1}$ in an excellent $80 \%$ isolated yield (Figure 3, entry 14). We were unable to unequivocally determine the selectivity of these transformations by examination of the crude reaction mixture by ${ }^{1} \mathrm{H}$ NMR spectroscopy; however, the major isomer could be isolated from both of these transformations in $63 \%$ and $80 \%$ yield respectively after purification by $\mathrm{SiO}_{2}$ column chromatography. Esters also proved to be effective substrates, ethyl propionate delivering the E-product 22 with excellent 6.5:1 selectivity and $77 \%$ isolated yield for the major E-isomer (Figure 3, entry 15). Interestingly, under the optimized conditions acetophenone gave the product of an aldol reaction in $93 \%$ yield. ${ }^{14}$

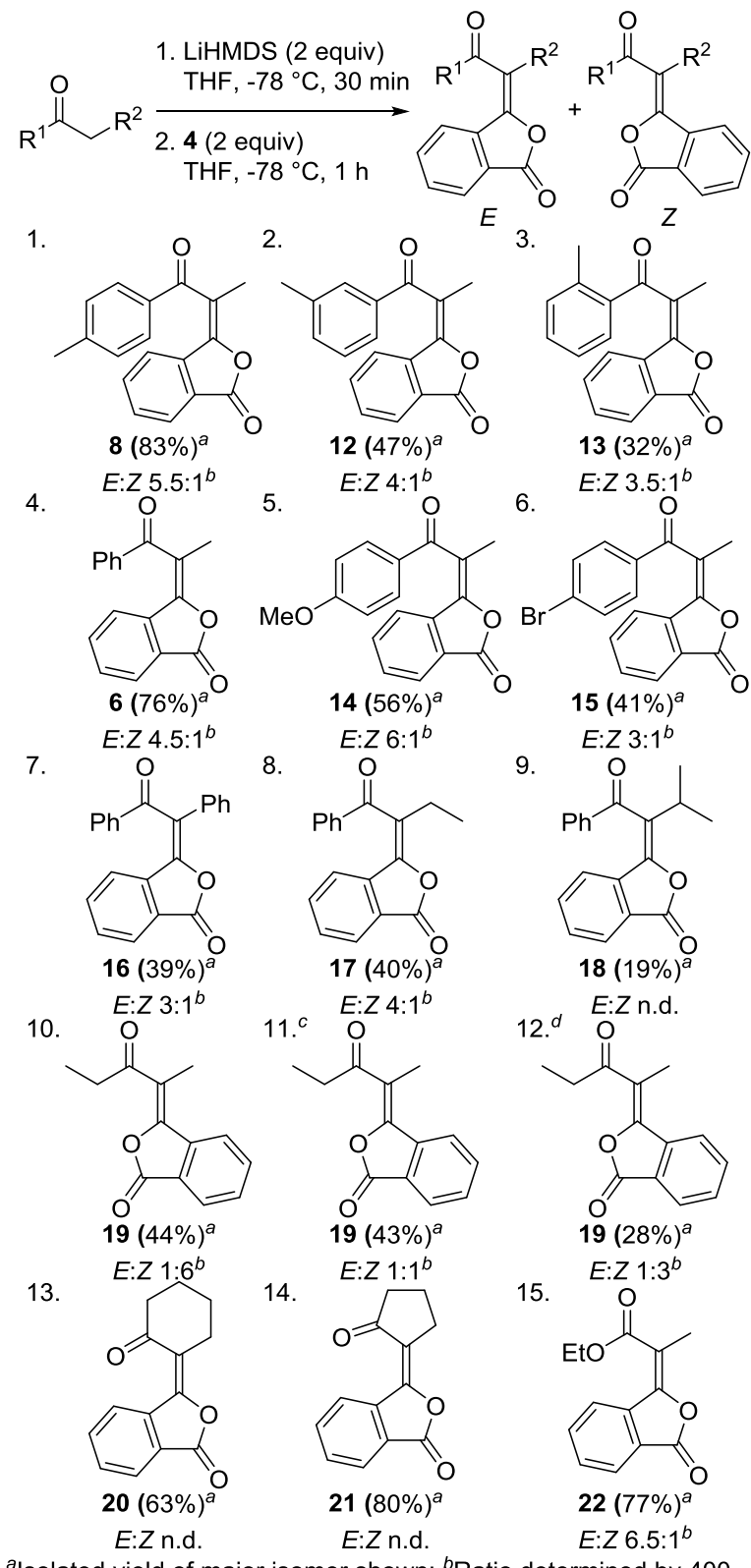

${ }^{a}$ Isolated yield of major isomer shown; ${ }^{b}$ Ratio determined by 400 $\mathrm{MHz}{ }^{1} \mathrm{H}$ NMR spectroscopy of crude reaction mixture in $\mathrm{CDCl}_{3}$; ${ }^{c} 23 \%$ v/v HMPA used as solvent; ${ }^{d}$ Toluene used as solvent.

Figure 3. Substrate scope.
Assignment of the relative stereochemistry of adducts prepared was based upon comparison of analytical data to reported literature values. ${ }^{10-13}$ Unequivocal reinforcement of this assignment came from X-ray crystallographic analysis of 8, 15, 19, 21 and 23 (see Supporting Information for full details).

Scheme 3. Isomerization of Alkylidene Benzofuranones.<smiles>C/C(C(=O)c1ccc(Br)cc1)=c1/oc(=O)c2ccccc2/c1=C(/C)C(=O)c1ccc(Br)cc1</smiles>

Stirring the E-isomer 15 at $25^{\circ} \mathrm{C}$ in neat sulfuric acid for $2.5 \mathrm{~h}$ led to isomerization of the double bond ( $E: Z 1: 3$ ), from which the thermodynamically more stable $Z$-isomer 23 could be isolated geometrically pure in $65 \%$ yield after purification by $\mathrm{SiO}_{2}$ column chromatography (Scheme 3). ${ }^{15}$ This provides rapid and convenient access to both isomeric forms of the alkylidene phthalide products. Resubmission of geometrically pure $\mathbf{2 3}$ to the isomerization conditions $\left(\mathrm{H}_{2} \mathrm{SO}_{4}, 2.5 \mathrm{~h}, 25^{\circ} \mathrm{C}\right)$ led to a thermodynamic $1: 3$ mixture of 15 and 23 , showing this isomerization is a fully reversible process.

Scheme 4. Further Transformations of Alkylidene Phthalides.<smiles>CNC(=O)c1ccccc1C(=O)NC</smiles>

$24(95 \%)$<smiles>[R]C(=O)OC([Ge][3H])/C(C)=C1\OC(=O)c2ccccc21</smiles>

$\mathrm{R}=\mathrm{Me} 26(77 \%)$<smiles></smiles>

8 $25^{\circ} \mathrm{C}, 2 \mathrm{~h}$ $\mathrm{CH}_{2} \mathrm{Cl}_{2}(0.25 \mathrm{M})$ rt, $0.5 \mathrm{~h}$

$25(66 \%)$ $\mathrm{R}={ }^{t} \mathrm{Bu} 27(91 \%)$
$\mathrm{Ac}_{2} \mathrm{O}\left(1.2\right.$ equiv) ${ }^{\wedge}$ or $\mathrm{PivCl}$ (1.3 equiv) $\mathrm{NEt}_{3}$ (1.2 equiv) Pyridine (3.0 equiv) DMAP $(10 \mathrm{~mol} \%)$ $\mathrm{CH}_{2} \mathrm{Cl}_{2}(0.2 \mathrm{M})$ rt, $18 \mathrm{~h}$<smiles>C/C(C(=O)O)=C1\OC(=O)c2ccccc21</smiles>

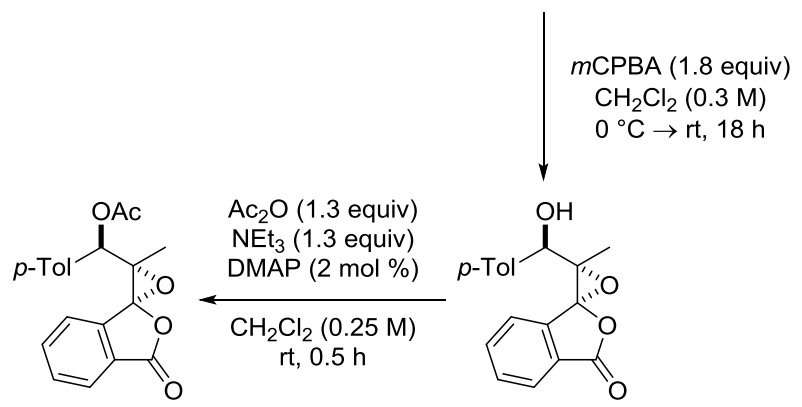

$29(91 \%)$

$28(81 \%)$

A series of further transformations of the alkylidene phthalides was explored (Scheme 4). Treatment of 8 with methylamine re- 
sulted in cleavage of the newly formed $\mathrm{C}=\mathrm{C}$ to give dimethylphthalamide 24 in $95 \%$ yield. Selective reduction of the ketone group was achieved by reaction of 8 under Luche conditions ${ }^{16}$ to give the alcohol 25 in $66 \%$ isolated yield without compromise in the stereochemical integrity of the double bond. O-Functionalization of the newly formed alcohol could be achieved through reaction with both acid anhydrides and acid chlorides in excellent yields (26 77\%; $2791 \%)$. Directed epoxidation of 25 with mCPBA (1.8 equiv) gave $\mathbf{2 8}$ stereoselectively ( $81 \%),{ }^{17}$ the relative stereochemistry of which was confirmed by single crystal X-ray crystallographic analysis of $\mathbf{2 9}$ (see Supporting Information for full details). Overall this series of transformations shows that each of the distinct functionalities within the core alkylidene phthalide product can be manipulated selectively allowing for effective diversification of the products.

In summary, the reagent 4 can be prepared in a single step by reaction of phthaloyl chloride with $N$-Boc hydroxylamine under basic reaction conditions. Treatment of enolates derived from $\mathrm{cy}$ clic or acyclic ketones as well as esters with 2 equiv of 4 leads to an alkylidene phthalide product stereoselectivity. The selectivity observed in the transformation can be altered by changing the polarity of the reaction medium. Isomerization of the products also proved possible under acidic conditions providing a convenient method by which to prepare this important class of heterocycle. The ability to manipulate the functional groups in the product suggests that this transformation will be applicable to the preparation of 3-substituted phthalides which are prevalent in many naturally occurring and biologically significant molecules.

\section{ASSOCIATED CONTENT}

\section{Supporting Information}

Analytical data, experimental procedures and NMR spectra for all compounds reported. This material is available free of charge via the Internet at http://pubs.acs.org.

\section{AUTHOR INFORMATION}

\section{Corresponding Author}

*Nicholas.Tomkinson@strath.ac.uk

\section{ACKNOWLEDGMENT}

The authors thank the University of Strathclyde for financial support and the EPSRC Mass Spectrometry Service, Swansea for highresolution spectra.

\section{REFERENCES}

(1) (a) Harvey, A. L.; Edrada-Ebel, R; Quinn, R. J. Nat. Rev. Drug Discovery 2015, 14, 111. (b) Cragg, G. M.; Newman, D. J. Biochim. Biophys. Acta 2013, 1830, 3670. (c) Newman, D. J.; Cragg, G. M. J. Nat. Prod. 2012, 75, 311. (d) Dias, D. A.; Urban, S.; Roessner, U. Metabolites 2012, 2, 303. (e) Mishra, B. B.; Tiwari, V. K. Eur. J. Med. Chem. 2011, 46, 4769. (f) Carter, G. T. Nat. Prod. Rep. 2011, 28, 1783. (h) Rishton, G. M. Am. J. Cardiol. 2008, 101, S43. (i) Harvey, A. L. Drug Discovery Today 2008, 13, 894.

(2) (a) Kim, J.; Kim, H.; Park, S. B. J. Am. Chem. Soc. 2014, 136 14629. (b) Lachance, H.; Wetzel, S.; Kumar, K.; Waldmann, H. J. Med.Chem. 2012, 55, 5989. (c) Cordier, C.; Morton, D.; Murrison, S.; Nelson, A.; O’Leary-Steele, C. Nat. Prod. Rep. 2008, 25, 719. (d) Newman, D. J. J. Med. Chem. 2008, 51, 2589. (e) Klekota, J.; Roth, F. P. Bioinformatics 2008, 24, 2518. (f) Evans, B. E.; Rittle, K. E.; Bock, M. G.;
DiPardo, R. M.; Freidinger, R. M.; Whitter, W. L.; Lundell, G. F.; Veber, D. F.; Anderson, P. S.; Chang, R. S. L.; Lotti, V. J.; Cerino, D. J.; Chen, T. B.; Kling, P. J.; Kunkel, K. A.; Springer, J. P.; Hirshfield, J. J. Med. Chem. 1988, $31,2235$.

(3) (a) O'Connor, C. J.; Beckmann, H. S. G.; Spring, D. R. Chem. Soc. Rev. 2012, 41, 4444. (b) Wetzel, S.; Bon, R. S.; Kumar, K.; Waldmann, H. Angew. Chem., Int. Ed. 2011, 50, 10800.

(4) (a) Karmakar, R.; Pahari, P.; Mal, D. Chem. Rev. 2014, 114, 6213. (b) Di Mola, A.; Palombi, L.; Massa, A. Curr. Org. Chem. 2012, 16, 2302. (c) Beck, J. J.; Chou, S.-C. J. Nat. Prod. 2007, 70, 891. (d) Xioang, M. J.; Li, Z. H. Curr. Org. Chem. 2007, 11, 833. (e) Lin, G.; Chan, S. S.-K.; Chung, H.-S.; Li, S.-L. Chemistry and Biological Action of Natural Occurring Phthalides. In Studies in Natural Products Chemistry Vol. 32; Atta-urRahman, Ed.; Elsevier: Amsterdam, 2005, 611.

(5) For reactions of phthaloyl peroxides see: (a) Greene, F. D. J. Am. Chem. Soc. 1956, 78, 2246. (b) Greene, F. D. J. Am. Chem. Soc. 1956, 78, 2250. (c) Greene, F. D.; Rees, W. W. J. Am. Chem. Soc. 1958, 80, 3432. (d) Greene, F. D. J. Am. Chem. Soc. 1959, 81, 1503. (e) Greene, F. D.; Adam, W.; Cantrill, J. E. J. Am. Chem. Soc. 1961, 83, 3461. (f) Jones, M., Jr.; DeCamp, M. R. J. Org. Chem. 1971, 36, 1536. (g) Yuan, C.; Axelrod, A.; Varela, M.; Danysh, L.; Siegel, D. Tetrahedron Lett. 2011, 52, 2540. (h) Yuan, C.; Liang, Y.; Hernandez, T.; Berriochoa, A.; Houk, K. N.; Siegel, D. Nature 2013, 499, 192. (i) Eliasen, M.; Thedford, R. P.; Claussen, K. R.; Yuan, C.; Siegel, D. Org Lett. 2014, 16, 3628. (j) Camelio, A. M.; Liang, Y.; Eliasen, A. M.; Johnson, T. C.; Yuan, C.; Schuppe, A. W.; Houk, K. N.; Siegel, D. J. Org. Chem. 2015, 80, 8084. (k) Eliasen, A. M.; Christy, M.; Claussen, K. R.; Besandre, R.; Thedford, R. P.; Siegel, D. Org. Lett. 2015, 17,4420 .

(6) For reactions of malonoyl peroxides see: (a) Griffith, J. C.; Jones, K. M.; Picon, S.; Rawling, M. J.; Kariuki, B. M.; Campbell, M.; Tomkinson, N. C. O. J. Am. Chem. Soc. 2010, 132, 14409. (b) Picon, S.; Rawling, M.; Campbell, M.; Tomkinson, N. C. O. Org. Lett. 2012, 14, 6250. (c) Jones, K. M.; Tomkinson, N. C. O. J. Org. Chem. 2012, 77, 921. (d) Rawling, M. J.; Rowley, J. H.; Campbell, M.; Kennedy, A. R.; Parkinson, J. A.; Tomkinson, N. C. O. Chem. Sci. 2014, 5, 1777. (e) Dragan, A.; Kubczyk, T. M.; Rowley, J. H.; Sproules, S.; Tomkinson. N. C. O. Org. Lett. 2015, 17, 2618. (f) Alamillo-Ferrer, C.; Davidson, S. C.; Rawling, M. J.; Theodoulou, N. H.; Campbell, M.; Humphreys, P. G.; Kennedy, A. R.; Tomkinson. N. C. O. Org. Lett. 2015, 17, 5132. (g) Terent'ev, A. O.; Vil, V. A.; Mulina, O. M.; Pivnitsky, K. K.; Nikishin, G. I. Mendeleev Commun. 2014, 24, 345 (h) Terent'ev, A. O.; Vil, V. A.; Nikishin, G. I.; Adam, W. Synlett 2015, 26, 802. (i) Trent'ev, A. O.; Vil, V. A.; Gorlov, E. S.; Nikishin, G. I.; Pivnitsky, K. K.; Adam, W. J. Org. Chem. 2016, 81, 810.

(7) Russell, K. E. J. Am. Chem. Soc. 1955, 77, 4814.

(8) Compound 4 has been synthesised previously and investigated as a pro-inhibitor of serine $\beta$-lactamases. (a) Zinner, G.; Ruthe, V.; Hitze, M.; Vollrath, R. Synthesis 1971, 148. (b) Tilvawala, R.; Pratt, R. F. Biochemistry 2013, 51, 7060 .

(9) Kato, H.; Tezuka, H.; Yamaguchi, K.; Nowada, K.; Nakamura, Y. J. Chem. Soc., Perkin Trans. 1 1978, 1029.

(10) Abell, A. D.; Clark, B. M.; Robinson, W. T. Aust. J. Chem. 1988, $41,1243$.

(11) Coelho, F.; Veronese, D.; Pavam, C. H.; de Paula, V. I.; Buffon, R. Tetrahedron 2006, 62, 4563.

(12) Mor, S.; Dhawan, S. N.; Kapoor, M.; Kumar, D. Tetrahedron 2007, 63, 594.

(13) For alternative methods for the preparation of this class of heterocycle see reference 4 .

(14) Allan, J. F.; Henderson, K. W.; Kennedy, A. R. Chem. Commun. 1999, 1325.

(15) Mukhopadhyay, R.; Kundu, N. G. Tetrahedron 2001, 57, 9475.

(16) Luche, J. L. J. Am. Chem. Soc. 1978, 100, 2226.

(17) Davies, S. G.; Fletcher, A. M.; Thomson, J. E. Org. Biomol. Chem. 2014, 12, 4544. 

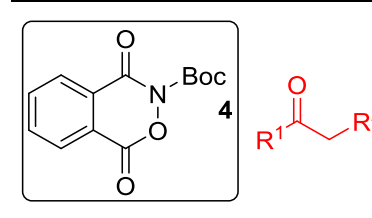

1. LiHMDS (2 equiv)
THF, $-78^{\circ} \mathrm{C}, 30 \mathrm{~min}$
$\begin{gathered}\text { 2. } 4(2 \text { equiv) } \\ \text { THF, }-78^{\circ} \mathrm{C}, 1 \mathrm{~h}\end{gathered}$

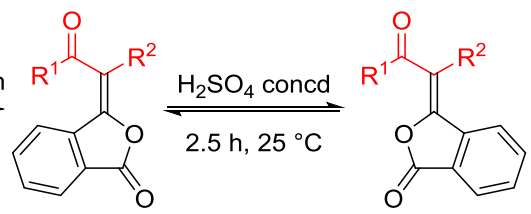

15 examples up to $83 \%$ yield up to $6.5: 1 \mathrm{dr}$ 